Check for updates

Cite this: New J. Chem., 2018, 42, 1092

Received 18th September 2017, Accepted 4th December 2017

DOI: 10.1039/c7nj03562d

rsc.li/njc

\section{Copper nanoparticles grafted on carbon microspheres as novel heterogeneous catalysts and their application for the reduction of nitrophenol and one-pot multicomponent synthesis of hexahydroquinolines $\dagger$}

\author{
Tibor Pasinszki, (D) *a Melinda Krebsz, (D) a Győző György Lajgut, (D) a Tünde Kocsis, ${ }^{\text {b }}$ \\ László Kótai, (D) ${ }^{\mathrm{b}}$ Sushama Kauthale, ${ }^{\mathrm{C}}$ Sunil Tekale ${ }^{\mathrm{c}}$ and Rajendra Pawar ${ }^{\mathrm{c}}$
}

\begin{abstract}
Novel carbon microsphere-supported metallic copper nanoparticles (Cu-NP/C) were synthesized using a low-cost and facile method based on carbonising a styrene-based, chelate-forming cation exchange resin loaded with $\mathrm{Cu}^{2+}$ ions. The metal-organic framework served as both copper and carbon source. CU-NP/C microspheres were characterized by XRD, Raman, SEM, TGA, EDAX, and BET surface area analyser and were employed as heterogeneous catalysts for the reduction of 4-nitrophenol to 4-aminophenol by $\mathrm{NaBH}_{4}$ and for the synthesis of medicinally significant hexahydroquinoline derivatives based on the one-pot, multi-component reaction of aldehydes, dimedone, ethyl acetoacetate, and ammonium acetate. The sustainable and cheap starting material, the relatively easy synthetic procedure, the catalytic efficiency, and the easy separation and reusability of $\mathrm{Cu}-\mathrm{NP} / \mathrm{C}$ microspheres open the door for their wide-scale application.
\end{abstract}

\section{Introduction}

Catalysis is at the heart of chemical transformations; therefore, there are continuous efforts to develop new catalysts and increase catalytic performance for various applications. Metallic nanoparticles (NPs) have become essential tools for many chemical processes employed in industry and academia during recent decades. ${ }^{1-5}$ NPs possess high specific surface area, various shapes and sizes, and high reactivity, and they often exhibit activity different from that of the corresponding bulk materials, due to their distinctive quantum properties. Handling of NPs, however, is not easy, because NPs are often prone to self-aggregation, and it is difficult to separate them from reaction media because the classical, convenient filtration

\footnotetext{
${ }^{a}$ ELTE Eötvös Loránd University, Institute of Chemistry, Budapest, $H-1117$, Hungary.E-mail: pasinszki@chem.elte.hu

${ }^{b}$ Research Centre for Natural Sciences, Hungarian Academy of Sciences, Budapest, H-1519, Hungary

${ }^{c}$ Department of Chemistry, Deogiri College, Station Road, Aurangabad (MS), 431 005, India

$\dagger$ Electronic supplementary information (ESI) available: Figures containing results of TG, EDAX, Raman, SEM, sorption, NMR, MS, and UV measurements; plot of 4NP reduction kinetics; schemes for the synthesis of microspheres and mechanism of polyhydroquinoline formation; tables containing XRD and BET results, and melting points. See DOI: 10.1039/c7nj03562d
}

methods are not applicable. One economical way to overcome or minimise these limitations is to anchor NPs on supports, with the latter also serving as modifiers of catalytic properties. Nowadays, economic considerations and health issues are gaining more and more importance, and the development of catalytic NPs that are inexpensive, non- or minimally-poisonous, highly active, selective, stable, robust, and easily separable from a reaction mixture is highly desirable. $\mathrm{Cu}$ NPs provide a very promising alternative to heavy metal NP catalysis, ${ }^{1}$ and the aim of the present work is to provide a novel route to carbon microsphere-supported Cu NPs and to test their catalytic activity in two selected reactions, namely, the reduction of 4-nitrophenol (4NP) and one-pot multicomponent synthesis of hexahydroquinolines. The combination of reactive NPs with microsized support is important for keeping the high activity of NPs while providing a possibility for easy catalyst handling and separation. We show in this paper that both Cu NPs and carbon support can be simultaneously and economically prepared by carbonising copper ionloaded, styrene-based cation exchange resins without using any additional reducing agent. Several carbon-supported Cu-based NPs have been prepared previously using wet-chemical, photochemical, electrochemical, and microwave methods, as well as thermal treatments, and their synthesis was reviewed last year. ${ }^{1}$

The reduction of $4 \mathrm{NP}$ by $\mathrm{NaBH}_{4}$ to 4 -aminophenol (4AP) is an industrially important reaction ${ }^{6}$ and a widely used model 
reaction to test the catalytic performance of metal nanocatalysts, due to the following reasons: (1) 4AP is the sole product of this reaction. (2) The reaction does not proceed at ambient temperature without a catalyst. (3) The reaction can be easily observed by a colour change from yellow (4NP) to colourless (4AP) and monitored by $\mathrm{UV} / \mathrm{vis}$ spectroscopy following the decrease of the absorption band of 4-nitrophenolate anion at $400 \mathrm{~nm} .{ }^{6,7}$ The reaction was shown to follow pseudo-first-order kinetics in the presence of a large excess of $\mathrm{NaBH}_{4}$, and the catalytic rate could be evaluated using first-order kinetics with respect to the 4-nitrophenolate concentration. $^{6-9}$

Hexahydroquinolines (HHQs) are biologically active compounds and find applications in medicinal chemistry as anticancer, antimicrobial, antihypertensive, and antimalarial agents. ${ }^{10-14}$ HHQs, in general, are synthesized by the four-component Hantzsch's condensation reaction, involving various aldehydes, dimedone, ethyl acetoacetate, and ammonium acetate. Several homogeneous and heterogeneous catalysts such as inorganic salts, Bronsted and Lewis acids, ionic liquids, metal oxides, and zeolites were reported to be active in the condensation reaction. ${ }^{15-21}$ Many of these methods, however, involve synthetic problems associated with difficult separation processes and expensive, hardly available, or non-recoverable catalysts, expensive reagents, or long reaction time. Considering the widespread applications of HHQ derivatives, there is a need to develop new and efficient catalysts for the green synthesis of these heterocyclic compounds. Therefore, our aim was to develop a facile and cheap catalyst system for Hantzsch's HHQ synthesis by selecting nanosized copper as the catalytically active metal and carbon microspheres as the catalyst support.

In this paper, we present a novel method for synthesizing copper NP-decorated carbon microspheres, their characterisation, including the determination of their phase composition and morphology, and their application as heterogeneous catalysts in $4 \mathrm{NP}$ reduction and HHQ synthesis.

\section{Results and discussion}

\section{Synthesis and characterization of $\mathrm{Cu}-\mathrm{NP} / \mathrm{C}$ microspheres}

In order to synthesize $\mathrm{Cu}$ NP-loaded carbon microspheres (Cu-NP/C), a commercial styrene-based chelate-forming ion exchanger resin containing iminodiacetate $\left(-\mathrm{CH}_{2} \mathrm{~N}\left(\mathrm{CH}_{2} \mathrm{COOH}\right)_{2}\right)$ functional groups with a binding capacity of $1 \mathrm{~mol}$ divalent metal cation per $1 \mathrm{dm}^{3}$ resin was selected as both the carbon source and $\mathrm{Cu}$ ion binder (see Experimental section). We expected that the carbonisation of copper ion-loaded resin produces not only the carbon support but also a reductive environment for the formation of metallic copper. Since copper ions were distributed in the resin according to iminodiacetate functional groups, the formation of only small $\mathrm{Cu}$ particles was expected, due to diffusion at the carbonisation temperature. We note that iminodiacetate chelating functional groups selectively bind one equivalent of $\mathrm{Cu}(\mathrm{II})$ ions (see Scheme S1, ESI $\dagger$ ). To find information about the stability and decomposition of loaded resin, thermogravimetric (TG) analysis was carried out. This latter indicated resin decomposition between 180 and $450{ }^{\circ} \mathrm{C}$

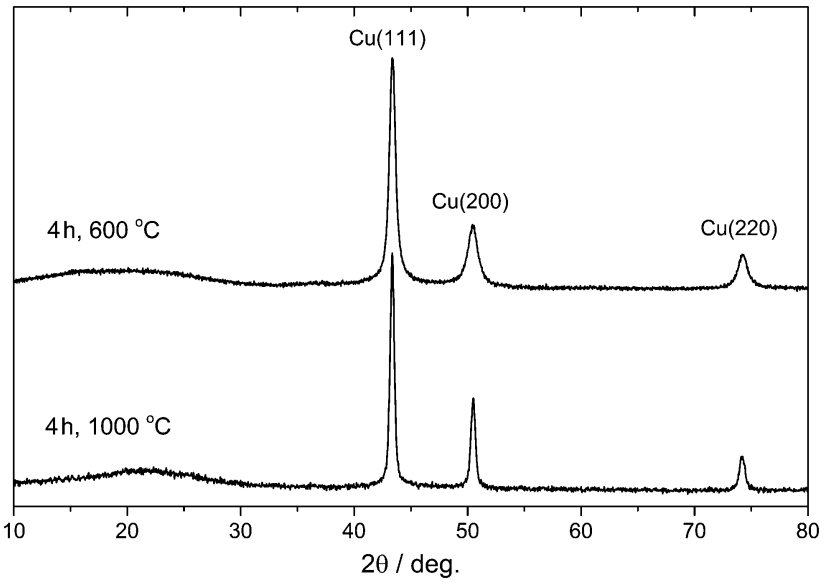

Fig. 1 Powder X-ray diffractogram of selected Cu-NP/C microspheres (carbonisation time and temperature are indicated).

and a complete weight loss of $68.2 \%$ up to $900{ }^{\circ} \mathrm{C}$ (see Fig. S1, $\mathrm{ESI} \dagger)$. Therefore, carbonisation of the resin was investigated in the 500-1000 ${ }^{\circ} \mathrm{C}$ temperature range in $100{ }^{\circ} \mathrm{C}$ increments, and the effect of heating time was studied by performing experiments for 2,4 , and 8 hours. The $\mathrm{Cu}$ content of microspheres prepared by carbonisation at $600{ }^{\circ} \mathrm{C}$ for 4 hours was determined to be $8.1 \%$ using ICP-OES after digesting microspheres in hot chromic acid. The Cu content on these microspheres' surfaces was measured to be $0.2 \%$ after dissolving surface $\mathrm{Cu}$ in $34 \%$ aqueous nitric acid.

The phase composition of synthesized $\mathrm{Cu}-\mathrm{NP} / \mathrm{C}$ microspheres was determined by powder X-ray diffraction (XRD). Representative XRD diffractograms are shown in Fig. 1. The XRD study unambiguously indicated that only metallic copper was formed as the sole crystalline phase during carbonisation between 600 and $1000{ }^{\circ} \mathrm{C}$, and besides $\mathrm{Cu}$, a small amount of $\mathrm{Cu}_{2} \mathrm{O}$ appeared at $500{ }^{\circ} \mathrm{C}$ carbonisation $(8,6$, and 3 at $\%$ of total $\mathrm{Cu}$ content, applying a heating time of 2,4 , and 8 hours, respectively; see Table S1, ESI $\dagger$ ). The average crystallite size of copper particles was calculated to be $15 \mathrm{~nm}$ at $500{ }^{\circ} \mathrm{C}$ using the Scherrer equation, and it increased gradually up to $35 \mathrm{~nm}$ with increasing carbonisation temperature (see Table S1, ESI $\dagger$ ). EDAX investigations indicated the presence of copper on the surface or close to the surface of microspheres (see Fig. S2, ESI $\dagger$ ). No graphitisation was observed by XRD.

Raman spectroscopy confirmed the carbonisation of the resin (Fig. S3, ESI $\dagger$ ), and selected spectra are shown in Fig. 2. The appearance of characteristic D, D', G, and 2D Raman bands at 1329-1347, 1162-1240 (shoulder), 1588-1599, and 2660$2700 \mathrm{~cm}^{-1}$, respectively, as well as the $\mathrm{D} / \mathrm{G}$ band intensity ratio, are characteristic of amorphous carbon. ${ }^{22}$ The graphitisation of the carbonaceous material, according to Raman spectra, is very low, in agreement with XRD. Raman bands characteristic of amorphous carbon appear on top of a broad background luminescence at $500{ }^{\circ} \mathrm{C}$ carbonisation, indicating imperfect carbonization at this temperature. This background, however, gradually decreases and disappears with increasing carbonisation time and temperature, respectively (Fig. 2 and Fig. S3, ESI $\dagger$ ). The measured Raman intensity, in general, decreases with increasing carbonisation 


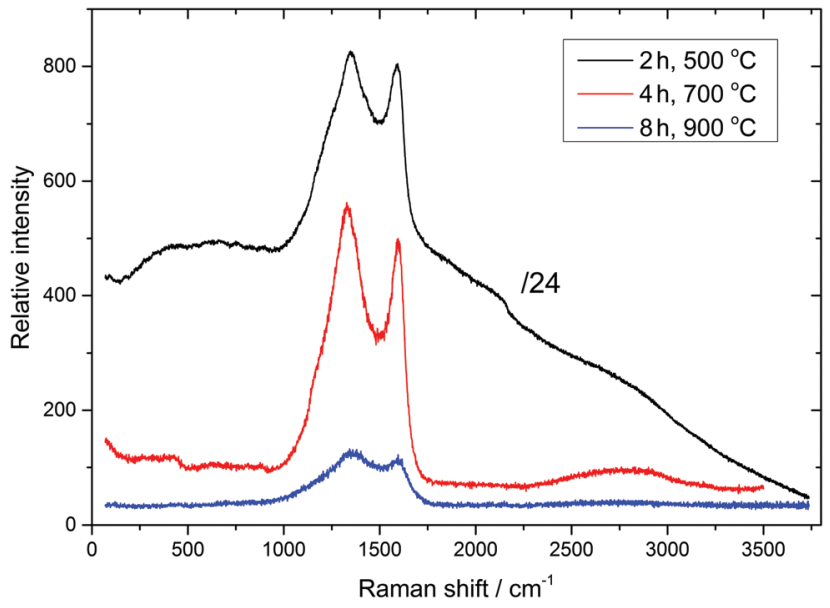

Fig. 2 Raman spectra of selected Cu-NP/C microspheres (carbonisation time and temperature are indicated, see also Fig. S3, ESI $\dagger$ ).

temperature, which indicates gradual replacement of $\mathrm{sp}^{3}$ carbon atoms by $\mathrm{sp}^{2}$ carbon atoms. Raman spectra of microspheres obtained by carbonisation between 600 and $1000{ }^{\circ} \mathrm{C}$ for 4 and 8 hours are very similar at the given temperature, indicating similar structural organisation of carbon microsphere surfaces.

The shape and surface morphology of synthesized microspheres were studied by scanning electron microscopy (SEM). $\mathrm{Cu}-\mathrm{NP} / \mathrm{C}$ microspheres inherited the spherical morphology of ion exchange resins (see Fig. S4, ESI $\dagger$ ), but their diameter decreased to half, $300-500 \mu \mathrm{m}$, due to shrinkage during the heat treatment. According to SEM, Cu NPs were distributed all over the surface of carbon microspheres. After some microspheres were broken in a mortar, SEM confirmed the distribution of $\mathrm{Cu}$ NPs inside the microspheres, too. Tiny Cu NPs are clearly visible on the surface of microspheres obtained by carbonisation at 500 and $600{ }^{\circ} \mathrm{C}$, but they tend to be embedded into the carbon matrix at higher temperatures. A carbon collar forms around $\mathrm{Cu}$ NPs at about $800{ }^{\circ} \mathrm{C}$, and NPs disappear in a seemingly fluffy carbon matrix at higher temperatures (Fig. 3 and Fig. S5-S7, ESI $\dagger$ ). SEM investigations thus suggest that $\mathrm{Cu}-\mathrm{NP} / \mathrm{C}$ microspheres prepared at around $600{ }^{\circ} \mathrm{C}$ are the most promising candidates for catalytic applications. Cu NPs are known to be slowly oxidized by oxygen in air, ${ }^{1}$ and it was fortuitous for this study that microspheres synthesized two years ago and stored in a closed container but under air could be reinvestigated by XRD. The old samples prepared at $600{ }^{\circ} \mathrm{C}$ indicated the partial oxidation of copper $\left(20 \mathrm{wt} \%\right.$ of $\mathrm{Cu}$ was oxidized to $\mathrm{Cu}_{2} \mathrm{O}$, possibly the surface content), but microspheres prepared at $1000{ }^{\circ} \mathrm{C}$ were practically unchanged (see Fig. S8 and S9, ESI $\dagger$ ). This confirmed that Cu NPs were embedded in the carbon matrix and protected from air in the case of high-temperature synthesis. The specific surface area of microspheres was determined using nitrogen adsorption measurements and found to be between 3 and $9 \mathrm{~m}^{2} \mathrm{~g}^{-1}$ (Table S1, ESI $\dagger$ ). The total pore volume for the sample prepared by carbonisation at $600{ }^{\circ} \mathrm{C}$ for 4 hours was measured to be only $0.0017 \mathrm{~cm}^{3} \mathrm{~g}^{-1}$, and the average pore width was estimated to be $2.2 \mathrm{~nm}$. The measured nitrogen sorption isotherms suggested poorly developed microand mesopores (see Fig. S10, ESI $\dagger$ ).
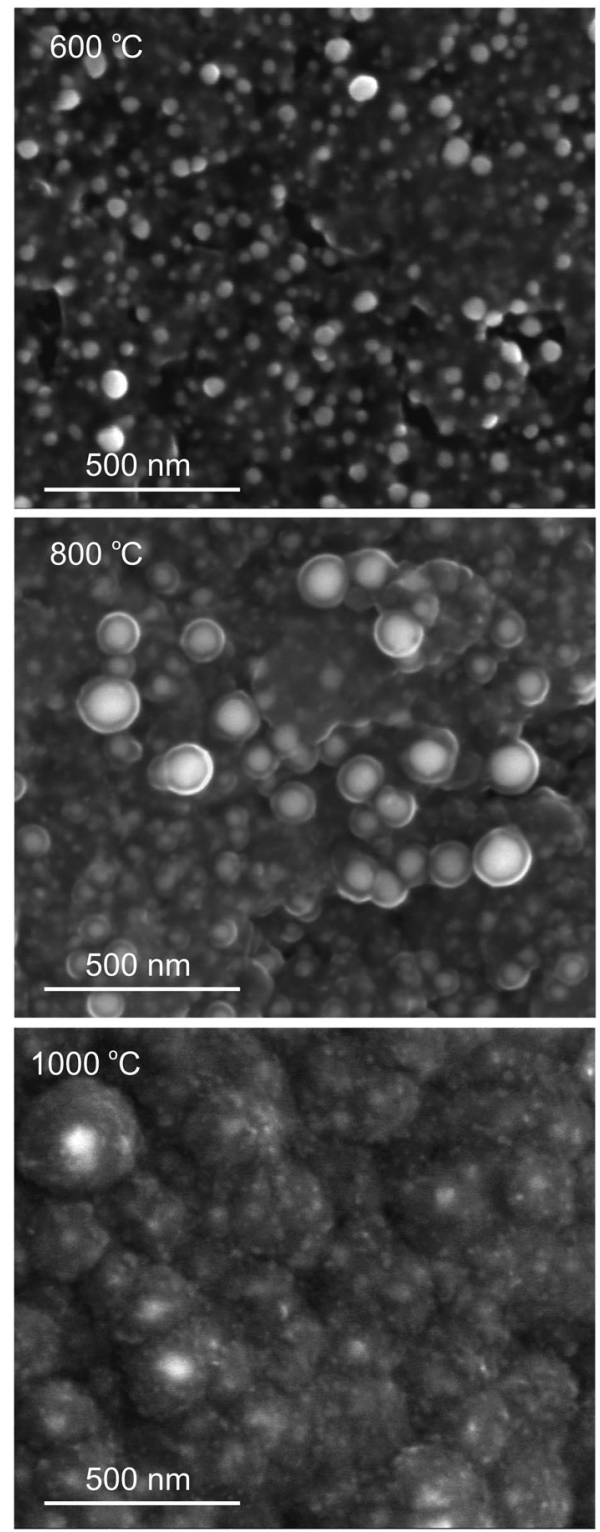

Fig. 3 SEM image of the Cu-NP/C microsphere surface obtained by carbonisation of the copper-loaded ion exchange resin at 600,800 , and $1000{ }^{\circ} \mathrm{C}$ for $8 \mathrm{~h}$ (see also Fig. S5-S7, ESI $\dagger$ ).

\section{Catalytic activity of $\mathrm{Cu}-\mathrm{NP} / \mathrm{C}$ microspheres for the reduction of 4-nitrophenol}

The Cu-NP/C sample prepared by carbonisation at $600{ }^{\circ} \mathrm{C}$ for 4 hours was selected for catalytic efficiency evaluation. $4 \mathrm{NP}$ was treated with a large excess of $\mathrm{NaBH}_{4}$ in water and in the presence of various amounts of catalysts (initial concentrations of $4 \mathrm{NP}$ and $\mathrm{NaBH}_{4}$ were $0.1 \mathrm{mM}$ and $10 \mathrm{mM}$, respectively) at $20{ }^{\circ} \mathrm{C}$, and the reaction was monitored by UV/vis spectroscopy. The characteristic absorption band of nitrophenolate anion appeared at $400 \mathrm{~nm}$. Upon addition of $\mathrm{Cu}-\mathrm{NP} / \mathrm{C}$ microspheres, the absorption band decreased with time, and that of $4 \mathrm{AP}$ at $300 \mathrm{~nm}$ increased. The $4 \mathrm{NP}$ concentration decrease versus reaction time is shown in Fig. 4 . No reaction between $4 \mathrm{NP}$ and $\mathrm{NaBH}_{4}$ was observed in the absence of $\mathrm{Cu}-\mathrm{NP} / \mathrm{C}$ microspheres (Fig. 4). 



Fig. 4 (A) Concentration of 4NP versus time for the 4NP reduction by $\mathrm{NaBH}_{4}$ in the presence of $\mathrm{Cu}-\mathrm{NP} / \mathrm{C}$ microspheres (amount of catalyst used is indicated; initial $4 \mathrm{NP}$ and $\mathrm{NaBH}_{4}$ concentrations are 0.1 and $10 \mathrm{mM}$; catalyst was added to mixed solutions of $4 \mathrm{NP}$ and $\mathrm{NaBH}_{4}$ (a and b); 4NP solution was stirred with the catalyst for 10 min before adding $\mathrm{NaBH}_{4}$ solution $(\mathrm{c}-\mathrm{e})$, temperature $=20^{\circ} \mathrm{C}$ ). Time dependent evolution of UV/vis spectra of $4 \mathrm{NP}$ anion in the absence (B) and the presence (C) of $\mathrm{Cu}-\mathrm{NP} / \mathrm{C}$ catalyst showing the reduction of $4 \mathrm{NP}$ by $\mathrm{NaBH}_{4}$.

When $4 \mathrm{NP}$ and $\mathrm{NaBH}_{4}$ solutions were mixed and the catalyst was added, an induction time of about 9 min was observed for the reaction. However, when the catalyst was added to the $4 \mathrm{NP}$ solution, stirred for 10 minutes, and the $\mathrm{NaBH}_{4}$ solution was consecutively added, the reaction proceeded without any induction time. The induction time of the $4 \mathrm{NP}$ and $\mathrm{NaBH}_{4}$ reaction was noted previously ${ }^{6,9}$ and was explained by a slow nanoparticle surface reconstruction in the presence of $4 \mathrm{NP} .{ }^{9}$ Our observations are in line with this. In the presence of a large excess of $\mathrm{NaBH}_{4}$, the $4 \mathrm{NP}$ reduction reaction is ruled by first-order kinetics, indicated by the linear correlation of $-\ln \left(c_{t} / c_{0}\right)$ versus time (min) plots, where $c$ is the 4NP concentration at the given time (see Fig. S11, ESI $\dagger$ ). The apparent rate constant, $k_{\mathrm{app}}$, can be determined from the slope of the fitted line. Increasing the amount of the catalyst used, the rate constant increased due to the increasing number of active sites for the reaction. The ratio of the rate constant over the total weight of the Cu-NP/C catalyst, $k=k_{\text {app }} / m_{\text {cat }}$, where $m$ is the mass of catalyst used, was determined to be between 68 and $100 \min ^{-1} \mathrm{~g}^{-1}$. In separate experiments, Cu NPs were removed from the microsphere surface using 1:1 diluted nitric acid. These 'bare' carbon microspheres did not catalyse the 4NP reduction, confirming the importance and catalytic activity of $\mathrm{Cu}$ NPs in $4 \mathrm{NP}$ reduction. $\mathrm{Cu}-\mathrm{NP} / \mathrm{C}$ microspheres prepared by carbonisation at $1000{ }^{\circ} \mathrm{C}$ for 4 hours were also investigated, but negligible catalytic activity was observed $\left(k=4 \mathrm{~min}^{-1} \mathrm{~g}^{-1}\right.$; Fig. S12, ESI $\left.\dagger\right)$, which is in line with SEM investigations indicating embedding of Cu NPs in the carbon matrix at high temperature.

\section{Catalytic activity of $\mathrm{Cu}-\mathrm{NP} / \mathrm{C}$ microspheres in the one-pot multi-component synthesis of hexahydroquinolines}

The catalytic activity of Cu-NP/C microspheres prepared by carbonisation at $600{ }^{\circ} \mathrm{C}$ for 4 hours was investigated for the synthesis of HHQs via the four-component Hantzsch's condensation reaction (Scheme 1). The reaction was performed on a preparative scale, and thus was not monitored by spectroscopy. The reaction mixture was worked up using standard preparative methods, and isolated yields were determined in all cases. Instead of varying, the reaction time was fixed to two hours, and conclusion on catalytic activity was made on the basis of isolated product yields. For reactions with apparently lower rate, reaction time was increased in selected cases. In order to study the effect of solvent and catalyst concentration on product yield, the reaction between benzaldehyde $(1 \mathrm{mmol})$, dimedone $(1 \mathrm{mmol})$, ethyl acetoacetate $(1.2 \mathrm{mmol})$ and ammonium acetate $(1.5 \mathrm{mmol})$ was selected. The effect of solvent on the rate of reaction was studied in the presence of $5 \mathrm{mg}$ Cu-NP/C catalyst ( $c a .5 \mathrm{wt} \%$ of benzaldehyde used). Among various screened solvents, namely, methanol, ethanol, isopropanol, 1,2-dichloroethane (DCE), THF, dioxane, and MeCN, ethanol was found to be the best in the studied model reaction concerning the yield of 2-amino-4-phenyl-3-cyano-7,7dimethyl-5-oxo-1,4,5,6,7,8-hexahydroquinoline (Table 1). Without catalyst, the yield of the reaction was very low, below $5 \%$ for each solvent. Using ethanol as the most appropriate solvent, the amount of catalyst was tested, and $10 \mathrm{mg}$ catalyst was found to be sufficient to complete the Hantzsch's transformation within 2 hours (Table 1 ).

In order to test the general applicability of $\mathrm{Cu}-\mathrm{NP} / \mathrm{C}$ catalyst for HHQ synthesis, the reaction of various ortho, meta, and para substituted benzaldehydes, two of them synthesized for the first time, and thiophene-2-aldehyde with dimedone, ethyl acetoacetate, and ammonium acetate was studied under the optimized conditions (ethanol, reflux, $10 \mathrm{mg}$ catalyst $/ 1 \mathrm{mmol}$ aldehyde). The catalyst was found to be efficient and provided excellent yields (82-94\%) for the investigated derivatives (Table 2). A plausible and stepwise mechanism for the fourcomponent reaction is suggested in Scheme S2 (ESI $\dagger$ ), analogous to that in ref. 15. It involves four possible steps: (1) The catalyst enhances the electrophilicity of the carbonyl carbon of aldehyde,

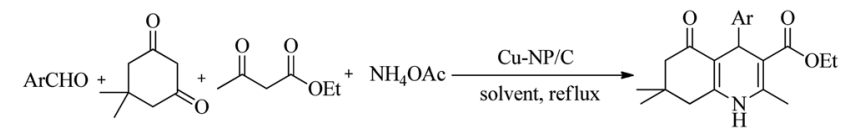

Scheme 1 Synthesis of hexahydroquinolines using Cu-NP/C catalyst.

Table 1 Solvent screening and optimisation of catalyst concentration

\begin{tabular}{llll}
\hline Entry $^{a}$ & Conditions & Catalyst $(\mathrm{mg})$ & Isolated yield (\%) \\
\hline 1 & THF, reflux, 5 h & 5 & 38 \\
2 & Dioxane, reflux, 5 h & 5 & 58 \\
3 & DCE, reflux, 3 h & 5 & 63 \\
4 & MeCN, reflux, 5 h & 5 & 74 \\
5 & iPrOH, reflux, 3 h & 5 & 76 \\
6 & MeOH, reflux, 2 h & 5 & 82 \\
7 & EtOH, reflux, 2 h & 5 & 87 \\
8 & EtOH, reflux, 2 h & 10 & 92 \\
9 & EtOH, reflux, 2 h & 15 & 94 \\
10 & EtOH, reflux, 2 h & 20 & 94
\end{tabular}

${ }^{a}$ See Scheme 1; $\mathrm{Ar}=$ phenyl; reagents: benzaldehyde $(1 \mathrm{mmol})$, dimedone $(1 \mathrm{mmol})$, ethyl acetoacetate $(1.2 \mathrm{mmol})$, ammonium acetate $(1.5 \mathrm{mmol})$, and solvent $(2 \mathrm{~mL})$. See Fig. S13-S15, ESI, for MS and NMR spectra. 
Table 2 Yields of various hexahydroquinolines using the Cu-NP/C catalyst

\begin{tabular}{lll}
\hline Entry $^{a}$ & Ar group & Isolated yield (\%) \\
\hline 11 & Phenyl & 92 \\
12 & 2,4-Dichlorophenyl & 88 \\
13 & 2-Chloro-4-fluorophenyl & 86 \\
14 & 4-Chlorophenyl & 94 \\
15 & 2-Fluorene & 90 \\
16 & 4-Methoxyphenyl & 89 \\
17 & 2-Hydroxyphenyl & 87 \\
18 & 3-Hydroxyphenyl & 89 \\
19 & 3-Nitrophenyl & 91 \\
20 & 4-Nitrophenyl & 88 \\
21 & 4-Bromophenyl & 87 \\
22 & 2-Thiophenyl & 82
\end{tabular}

${ }^{a}$ See Scheme 1 and Table S2, ESI; conditions: reflux, $2 \mathrm{~h}$, ethanol, $20 \mathrm{mg}$ catalyst, aldehyde $(2 \mathrm{mmol})$, dimedone $(2 \mathrm{mmol})$, ethyl acetoacetate $(2.4 \mathrm{mmol})$ and ammonium acetate $(3 \mathrm{mmol})$, solvent $5 \mathrm{~mL}$. See Fig. S13-S34, ESI, for MS and NMR spectra.

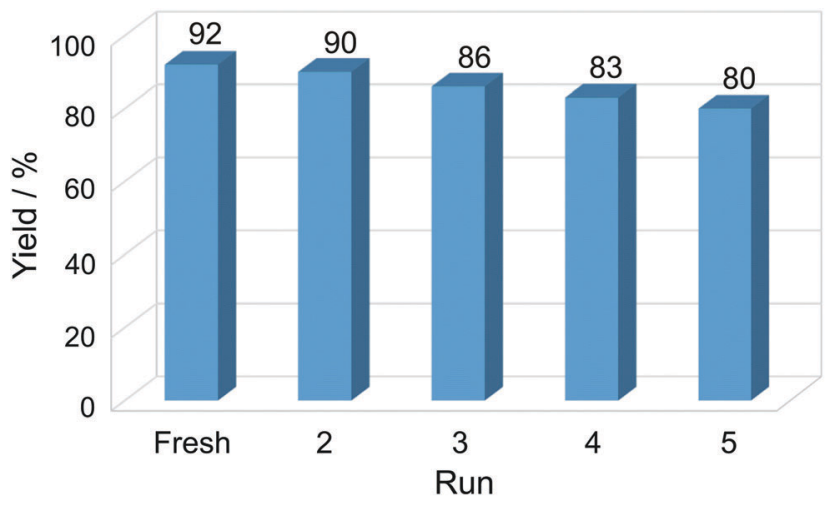

Fig. 5 Graphical representation of the reusability of the Cu-NP/C catalyst.

which reacts with the enolic form of dimedone to form arylidene intermediate (I). (2) Ethyl acetoacetate reacts with ammonium acetate to form $\beta$-enaminoester (II). (3) Arylidene intermediate (I) reacts with $\beta$-enaminoester (II), followed by (4) proton transfer and cyclization.

The reusability of the catalyst is important for practical applications, and it was studied by selecting the reaction between benzaldehyde, dimedone, ethyl acetoacetate and ammonium acetate, as well as the most favorable reaction conditions (ethanol, reflux, $10 \mathrm{mg}$ catalyst $/ 1 \mathrm{mmol}$ aldehyde) and 2 hours of reaction time. Experiments revealed that the Cu-NP/C catalyst could be consecutively reused four times without significant loss of catalytic activity (Fig. 5). The slight decrease in yield of the corresponding product, 2-amino-4-phenyl-3-cyano-7,7-dimethyl5-oxo-1,4,5,6,7,8-hexahydroquinoline, can be attributed to a small catalyst loss during its recovery and deactivation. The efficiency of the $\mathrm{Cu}-\mathrm{NP} / \mathrm{C}$ catalyst is compared to that of a number of previously reported heterogeneous catalysts in Table S3, ESI. $\dagger$

\section{Experimental}

\section{General information}

Chemicals were reagent grade from commercial sources and used without further purification. Identification of synthesized hexahydroquinolines was based on melting point and spectroscopic measurements. Melting points were measured in open capillaries using an Optics technology melting point apparatus and were uncorrected. ${ }^{1} \mathrm{H}$ NMR, ${ }^{13} \mathrm{C}$ NMR, and DEPT spectra were obtained on Bruker Avance 250 and 400 spectrometers and referenced to tetramethylsilane (TMS). Infrared (IR) spectra were recorded on a Shimadzu FTIR spectrometer (Prestige IR21) using neat samples. Samples were analyzed for exact mass on a mass analyzer (Waters-TQD).

\section{Synthesis of Cu-NP/C microspheres}

A styrene-based VARION BIM-7 commercial chelate-forming ion exchanger resin, containing $7 \%$ divinylbenzene crosslinker, $2 \%$ acrylonitrile modifier, and iminodiacetate $\left(-\mathrm{CH}_{2} \mathrm{~N}\left(\mathrm{CH}_{2} \mathrm{COOH}\right)_{2}\right)$ functional groups with a binding capacity of $1 \mathrm{~mol}$ divalent metal cation per $1 \mathrm{dm}^{3}$ resin was used as the starting material. The resin was saturated with $\mathrm{Cu}^{2+}$ ions using aqueous copper sulphate $\left(\mathrm{CuSO}_{4}\right)$ solution according to the procedure described in our previous studies. ${ }^{22,23}$ The exchanged resin was first dried in air and then placed in a drying box at $120{ }^{\circ} \mathrm{C}$ for 1 day. The dried resin was carbonized at 500, 600, 700, 800, 900, and $1000{ }^{\circ} \mathrm{C}$ for 2,4 , and $8 \mathrm{~h}$ in a high-purity dry nitrogen stream using an electric furnace. The furnace was heated to the desired temperature in $30 \mathrm{~min}$, then cooled down to room temperature naturally after heat treatment.

\section{Catalyst characterization}

X-ray powder diffraction measurements were done on a Model PW 3710/PW 1050 Bragg-Brentano diffractometer using Cu-K $\alpha$ radiation $(\lambda=1.541862 \AA)$. Raman spectra were recorded on a HORIBA JobinYvonLabRAM HR confocal Raman microscope using He-Ne excitation $(632 \mathrm{~nm})$ and a laser power of $0.1 \mathrm{~mW}$. BET specific surface area was determined using the volumetric method and nitrogen gas at liquid nitrogen temperature, using an ASDI RXM-100 catalyst characterization instrument. Samples were pre-treated in vacuum at $300{ }^{\circ} \mathrm{C}$ for 2 hours. TG measurements were performed on a modified Perkin-Elmer TGS-2 Thermo balance. A sample in a platinum sample pan was heated at $10{ }^{\circ} \mathrm{C} \mathrm{min}^{-1}$ up to $900{ }^{\circ} \mathrm{C}$ under nitrogen atmosphere. Scanning electron microscopy (SEM) and EDAX analysis were performed using an FEI Quanta 3D high-resolution microscope. Resolution of the instrument was $\leq$ $1.2 \mathrm{~nm}$ at $30 \mathrm{keV}$ accelerating voltage and in high vacuum. Spectrophotometric measurements were done using a Perkin-Elmer UV/vis Lambda 35 spectrometer applying a split width of $1 \mathrm{~nm}$. Cu content was measured by inductively coupled plasma optical emission spectrometry (ICP-OES) using a Spectro Genesis instrument.

\section{Reduction of 4-nitrophenol (4NP)}

Two stock solutions were prepared by dissolving $4 \mathrm{NP}$ and $\mathrm{NaBH}_{4}$ separately in distilled water. A quartz cuvette with an optical path length of $1 \mathrm{~cm}$ was consecutively charged with the catalyst (1, 2, or $4 \mathrm{mg}), 1.5 \mathrm{~cm}^{3} 0.2 \mathrm{mM} 4 \mathrm{NP}$ solution (stirred for 0 or 10 min before adding $\mathrm{NaBH}_{4}$ ), and $1.5 \mathrm{~cm}^{3} 20 \mathrm{mM} \mathrm{NaBH}_{4}$ solution. Concentrations of $4 \mathrm{NP}$ and $\mathrm{NaBH}_{4}$ in the initial solution were $0.1 \mathrm{mM}$ and $10 \mathrm{mM}$, respectively. The reaction mixture was stirred and monitored by UV/vis spectroscopy following the 
absorption band of $4 \mathrm{NP}$ anion at $400 \mathrm{~nm}$. The stirring was stopped while recording the UV/vis spectrum.

\section{General procedure for the synthesis of Hantzsch's hexahydroquinoline derivatives}

A mixture of aldehyde $(2 \mathrm{mmol})$, dimedone $(2 \mathrm{mmol})$, ethyl acetoacetate $(2.4 \mathrm{mmol})$, ammonium acetate $(3 \mathrm{mmol})$ and $\mathrm{Cu}-\mathrm{NP} / \mathrm{C}$ catalyst $(20 \mathrm{mg})$ in ethanol $(5 \mathrm{~mL})$ was refluxed for $2 \mathrm{~h}$. The progress of the reaction was monitored by TLC $(30 \%$ ethyl acetate: $n$-hexane). After completion of the reaction, the reaction mass was diluted with hot ethanol $(10 \mathrm{~mL})$ and filtered off to separate the catalyst. The filtrate was concentrated on a rotary evaporator to obtain the crude product, which was purified by recrystallization from ethanol to afford the corresponding pure hexahydroquinolines. The recovered catalyst was washed several times with hot ethanol, dried in an electric oven at $120{ }^{\circ} \mathrm{C}$ for about 30 minutes, and reused several times when it was required. Spectral data of newly synthesized compounds are as follows.

Ethyl-4-(2-chloro-4-fluorophenyl)-1,4,5,6,7,8-hexahydro-2,7,7trimethyl-5-oxoquinoline-3-carboxylate (Table 2, entry 13). M.p.: 180-181 ${ }^{\circ} \mathrm{C} ;{ }^{1} \mathrm{H}$ NMR (DMSO-d 6$): \delta=0.8(\mathrm{~s}, 3 \mathrm{H}), 1.19(\mathrm{t}, 3 \mathrm{H}), 1.9$ (dd, 1H), 1.99 (s, 3H), 2.1 (dd, 1H), 2.2 (s, 3H), 2.3 (dd, 1H), 2.4 (dd, 1H), 3.9 (q, 2H), 5.12 (s, 1H), 7.05 (dd, 1H), $7.13(\mathrm{dd}, 1 \mathrm{H})$, 7.25 (dd, 1H), 9.1 (s, 1H) ppm; ${ }^{13} \mathrm{C}$ NMR (DMSO-d $): \delta=14.1$, 18.2, 26.4, 29.0, 31.9, 34.5, 50.2, 58.9, 103.0, 109.4, 113.8, 115.6, 132.5, 141.6, 145.2, 149.7, 158.6, 161.0, 166.6, 193.9 ppm; IR(neat): 3270, 2902, 1780, 1670, 1604, 1060, 826, $890 \mathrm{~cm}^{-1}$; mass $(\mathrm{m} / \mathrm{z}): 392(\mathbf{M}+1)^{+}$.

Ethyl-4-(9H-fluoren-2-yl)-1,4,5,6,7,8-hexahydro-2,7,7-trimethyl5-oxoquinoline-3-carboxylate (Table 2, entry 15). M.p.: 224-225 ${ }^{\circ} \mathrm{C}$; ${ }^{1} \mathrm{H}$ NMR $\left(\right.$ DMSO-d $\left._{6}\right) \delta=0.9(\mathrm{~s}, 3 \mathrm{H}), 1.0(\mathrm{~s}, 3 \mathrm{H}), 1.19(\mathrm{~s}, 3 \mathrm{H}), 1.98$ (dd, 1H), 2.2 (dd, 1H), 2.3 (s, 3H), 2.5 (dd, 1H), 2.6 (dd, 1H), 3.8 (q, 2H), $4.0(\mathrm{~s}, 2 \mathrm{H}), 4.9(\mathrm{~s}, 1 \mathrm{H}), 7.19-7.35(\mathrm{~m}, 4 \mathrm{H}), 7.5(\mathrm{dd}, 1 \mathrm{H})$, 7.6-7.8 (dd, 2H), 9.1 (s, 1H) ppm; ${ }^{13} \mathrm{C}$ NMR (DMSO-d 6 ): $\delta=14.1,18.3,26.4,29.1,32.1,36.1,36.3,50.3,59.0,103.8,110.1$, 119.3, 119.6, 124.3, 125.0, 126.2, 126.4, 126.6, 138.8, 141.0, 142.4, 142.8, 144.8, 146.8, 149.4, 166.9, 194.3 ppm; IR(neat): 3279, 2957, 1703, 1649, 1210, $1072 \mathrm{~cm}^{-1}$; mass $(\mathrm{m} / \mathrm{z}): 428(\mathrm{M}+1)^{+}$.

\section{Conclusions}

In conclusion, we have developed a pyrolytic method for the synthesis of novel copper nanoparticle/carbon microsphere (Cu-NP/C) composites from Cu-loaded, iminodiacetate-functionalized, styrene-divinylbenzene copolymer (ion exchanger). The method is simple, cost-effective, and easy to scale-up for large-scale production. Microspheres have been characterized for their phase composition and surface morphology using various methods. Based on these observations, microspheres obtained by carbonising the ion exchanger at $600{ }^{\circ} \mathrm{C}$ for 4 hours have been selected for catalytic evaluation. The selected $\mathrm{Cu}-\mathrm{NP} / \mathrm{C}$ microspheres have demonstrated excellent catalytic activity for the reduction of 4-nitrophenol and for the one-pot, four-component synthesis of medicinally important hexahydroquinolines. Due to their facile and economical synthesis, reusability, activity, separability, and eco-friendliness, $\mathrm{Cu}-\mathrm{NP} / \mathrm{C}$ microspheres are expected to replace expensive noble metals in certain catalytic applications.

\section{Conflicts of interest}

There are no conflicts to declare.

\section{Acknowledgements}

We thank T. Váczi, I. Kovács, G. Varga, Sz. Klébert and Z. May for their assistance in instrumental measurements.

\section{Notes and references}

1 M. B. Gawande, A. Goswami, F.-X. Felpin, T. Asefa, X. Huang, R. Silva, X. Zou, R. Zboril and R. S. Varma, Chem. Rev., 2016, 116, 3722 .

2 L. He, F. Weniger, H. Neumann and M. Beller, Angew. Chem., Int. Ed., 2016, 55, 12582.

3 M. I. Din and R. Rehan, Anal. Lett., 2017, 50, 50.

4 Y. Liu, G. Zhao, D. Wang and Y. Li, Natl. Sci. Rev., 2015, 2, 150.

5 G. Prieto, H. Tüysüz, N. Duyckaerts, J. Knossalla, G.-H. Wang and F. Schüth, Chem. Rev., 2016, 116, 14056.

6 J. Noh and R. Meijboom, in Reduction of 4-Nitrophenol as a Model Reaction for Nanocatalysis, ed. A. K. Mishra, Application of Nanotechnology in Water Research, Scrivener Publishing LLC, 2014, ch. 13, pp. 333-406.

7 P. Zhao, X. Feng, D. Huang, G. Yang and D. Astruc, Coord. Chem. Rev., 2015, 287, 114.

8 D. Rambabu, C. P. Pradeep, Pooja and A. Dhir, New J. Chem., 2015, 39, 8130.

9 S. Wunder, F. Polzer, Y. Lu, Y. Mei and M. Ballauff, J. Phys. Chem. C, 2010, 114, 8814.

10 S. C. Jadhavar, H. M. Kasraliker, S. V. Goswami and S. R. Bhusare, Heterocycl. Lett., 2016, 6, 717.

11 N. R. Mohamed, N. Y. Khaireldin, A. F. Fahmy and A. A. El-Sayed, J. Heterocycl. Chem., 2013, 50, 1264.

12 H. M. Faidallah, S. A. F. Rostom, A. M. Asiri, K. A. Khan, M. F. Radwan and H. Z. Asfour, J. Enzyme Inhib. Med. Chem., 2013, 28, 123.

13 X. H. Yang, G. M. Xiao, Z. M. Wang, Y. H. Zhou and G. D. Feng, Adv. Mater. Res., 2012, 581-582, 7.

14 M. Vanaerschot, L. Lucantoni, T. Li, J. M. Combrinck, A. Ruecker, T. R. S. Kumar, K. Rubiano, P. E. Ferreira, G. Siciliano, S. Gulati, P. P. Henrich, C. L. Ng, J. M. Murithi, V. C. Corey, S. Duffy, O. J. Lieberman, M. I. Veiga, R. E. Sinden, P. Alano, M. J. Delves, K. L. Sim, E. A. Winzeler, T. J. Egan, S. L. Hoffman, V. M. Avery and D. A. Fidock, Nat. Microbiol., 2017, 2, 1403.

15 S. Sobhani, F. Zarifi and J. Skibsted, New J. Chem., 2017, 41, 6219.

16 E. Tabrizian and A. Amoozadeh, J. Chin. Chem. Soc., 2017, 64, 331. 
17 S.-J. Yu, S. Wu, X.-M. Zhao and C.-W. Lu, Res. Chem. Intermed., 2017, 43, 3121.

18 O. Goli-Jolodar, F. Shirini and M. Seddighi, RSC Adv., 2016, 6, 26026.

19 M. Abaszadeh, M. Seifi and A. Asadipour, Synth. React. Inorg., Met.-Org., Nano-Met. Chem., 2016, 46, 512.

20 A. Khazaei, A. R. Moosavi-Zare, H. Afshar-Hezarkhani and V. Khakyzadeh, RSC Adv., 2014, 4, 32142.
21 L. Nagarapu, M. D. Kumari, N. V. Kumari and S. Kantevari, Catal. Commun., 2007, 8, 1871.

22 T. Pasinszki, M. Krebsz, L. Kótai, I. E. Sajó, Z. Homonnay, E. Kuzmann, L. F. Kiss, T. Váczi and I. Kovács, J. Mater. Sci., 2015, 50, 7353.

23 L. Kótai, T. Pasinszki, Zs. Czégény, Sz. Bálint, I. Sajó, Z. May, P. Németh, Z. Károly, P. K. Sharma, V. Sharma and K. K. Banerji, Eur. Chem. Bull., 2012, 1, 398. 